\title{
Long-term effects of treatment and response in patients with chronic hepatitis $C$ on quality of life. An international, multicenter, randomized, controlled study
}

\author{
Geert Bezemer', Arthur R Van Gool ${ }^{1,2}$, Elke Verheij-Hart ${ }^{1}$, Bettina E Hansen ${ }^{1}$, Yoav Lurie ${ }^{3}$, Juan I Esteban ${ }^{4}$, \\ Martin Lagging ${ }^{5}$, Francesco Negro ${ }^{6}$, Stefan Zeuzem ${ }^{7}$, Carlo Ferrari ${ }^{8}$, Jean-Michel Pawlotsky ${ }^{9}$, Avidan U Neumann ${ }^{10}$, \\ Solko W Schalm ${ }^{1}$ and Robert I de Knegt ${ }^{1 *}$, for for the DITTO-HCV Study Group
}

\begin{abstract}
Background: Hepatitis $C$ decreases health related quality of life (HRQL) which is further diminished by antiviral therapy. HRQL improves after successful treatment. This trial explores the course of and factors associated with HRQL in patients given individualized or standard treatment based on early treatment response (Ditto-study).

Methods: The Short Form (SF)-36 Health Survey was administered at baseline ( $n=192)$ and 24 weeks after the end of therapy $(n=128)$.

Results: At baseline HRQL was influenced by age, participating center, severity of liver disease and income. Exploring the course of HRQL (scores at follow up minus baseline), only the dimension general health increased. In this dimension patients with a relapse or sustained response differed from non-responders. Men and women differed in the dimension bodily pain. Treatment schedule did not influence the course of HRQL.

Conclusions: Main determinants of HRQL were severity of liver disease, age, gender, participating center and response to treatment. Our results do not exclude a more profound negative impact of individualized treatment compared to standard, possibly caused by higher doses and extended treatment duration in the individualized group. Antiviral therapy might have a more intense and more prolonged negative impact on females.
\end{abstract}

Keywords: health related quality of life, hepatitis C, peginterferon

\section{Background}

Patients chronically infected with hepatitis $C$ virus $(\mathrm{HCV})$ have a decreased health related quality of life (HRQL) compared to the general population $[1,2]$. The impact of the disorder is comparable with other stressful life events and chronic diseases, like diabetes [3]. In part, the reduction in HRQL is due to the mental components of HRQL. With regard to these mental components, patients aware of their diagnosis have a more reduced HRQL than those who are unaware [4]. Furthermore, many $\mathrm{HCV}$ patients have a previous or

\footnotetext{
* Correspondence: r.deknegt@erasmusmc.nl

'Dpt. Gastroenterology \& Hepatology, Erasmus University Medical Center, Rotterdam, the Netherlands

Full list of author information is available at the end of the article
}

ongoing addiction and/or psychiatric problems, reflected in lower HRQL. In addition, patients with hepatitis C are stigmatized in society and the majority of the population of hepatitis $\mathrm{C}$ patients has a lower social economic status compared to the general population [5].

The reduction of HRQL is probably also due to physical and psychiatric symptoms as a direct consequence of this chronic infection and its sequelae (such as cirrhosis). The chronic inflammation is believed to signal the brain and to give rise to neurovegetative symptoms (e.g. malaise and fatigue) and to amongst others depression and concentration difficulties [6]. Possibly, also the brain itself is infected by HCV [7].

Finally, treatment of chronic HCV with (peg)interferon-alpha ((PEG)IFN) and ribavirin (RBV) further 
diminishes HRQL due to its side-effects. The introduction of PEGIFN provided a significant improvement over standard IFN, with the result that the decrease of HRQL during treatment with PEGIFN is less than with standard IFN [8-11]. In case of successful treatment (obtaining a sustained virological response (SVR)) an improvement of HRQL-scores is observed [2,8-10].

In the Ditto-study [12] a dynamically individualized treatment schedule depending on the on-treatment response was compared to a standard combination therapy with PEGIFN alfa-2a (180 $\mu \mathrm{g}$ qw) plus RBV (1000$1200 \mathrm{mg} \mathrm{qd}$ ) for 48 weeks (Figure 1). The primary aim of the Ditto study was to improve the SVR rate by individualizing the treatment schedule, but this could not be established.

This large scale, multi-centre, international trial, firstly, provides the opportunity to explore a variety of factors associated with HRQL in HCV patients at baseline (treatment naïve; $t=0$ ). Secondly, although type of treatment, treatment intensity and treatment duration were heterogeneous this study enabled us to investigate the course of HRQL during PEGIFN-based treatment and to add to the existing knowledge on the impact of cytokine-based antiviral treatment on HRQL. (E.g. do patients recover 24 weeks after completion of therapy (follow up) and which factors are associated with the course of HRQL?)

\section{Methods}

\section{Patients}

273 patients were included in the study, after informed consent was obtained, and 270 patients were randomized after 6 weeks of standard treatment. The ethical

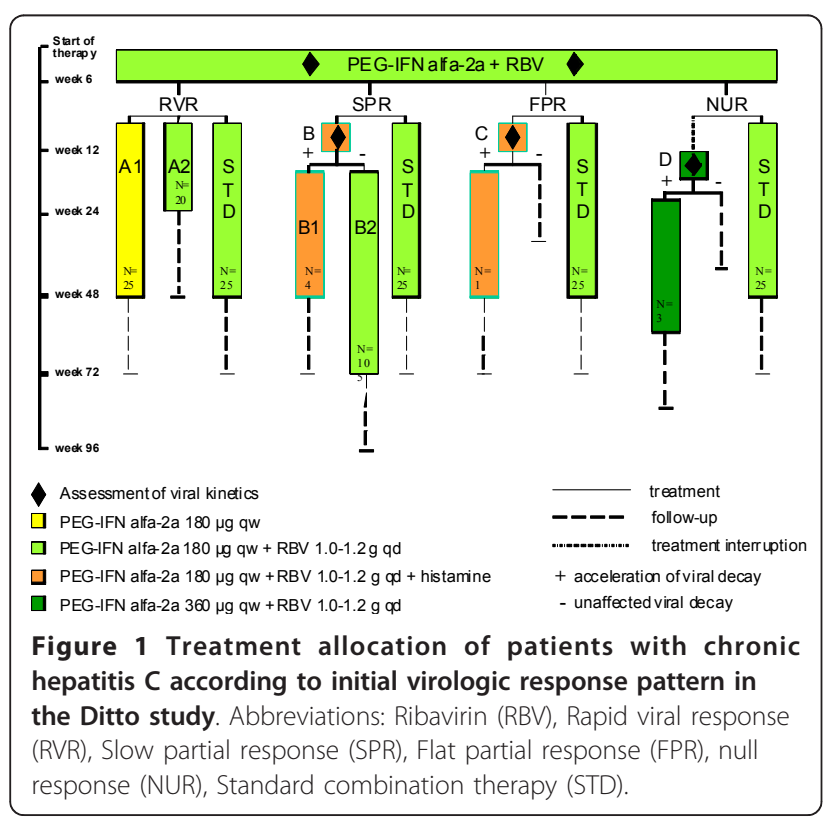

review boards of the participating centers approved the study. After randomization, 134 patients received standard treatment and 136 patients were treated according to an individualized treatment schedule depending on the response at week 4 and 12 of treatment. 216 patients completed the treatment per protocol and 249 patients completed the end of follow up. At $t=0 \mathrm{HRQL}$ was measured in 192 patients (not every center participated in the HRQL-analysis) and at follow up (24 weeks after completion of therapy) in 128 patients. In 120 patients, HRQL could be assessed at both time points.

\section{Study Design}

This phase III, open-label, randomized, multicenter trial was conducted by the DITTO-HCV study group between February 2001 and November 2003 at 9 centers in France, Germany, Greece, Israel, Italy, the Netherlands, Spain, Sweden, and Switzerland.

\section{Assessments}

The Short Form (SF)-36 Health Survey was used to measure HRQL. The SF-36 generates a profile of HRQL outcomes by measuring health across eight different dimensions: physical functioning, role limitation because of physical health, social functioning, vitality, bodily pain, mental health, role limitation because of emotional problems and general health. Responses to each question within a dimension are combined to generate a score from 0 to 100 , where 100 indicates "good health". The eight multi-item subscales were also converted into a physical component summary scale and a mental component summary scale [13]. Demographic (such as age, gender, and income in Euros) and disease related factors were assessed before start of treatment. At the moment the SF-36 was completed at follow up both patients and the treating physician were unaware of the response to the treatment because HCV-RNA testing results were not known yet, however non-responders were aware of their (positive) HCV-RNA status at relevant time points during treatment.

\section{Data analysis}

\section{Power calculation}

The HRQL-analysis was part of the main study which was powered on significant differences in SVR-rates between standard and individualized treatment. Therefore no separate power analysis was performed for this analysis.

\section{Determinants of HRQL before treatment}

To investigate the influence of different characteristics such as age, grade of fibrosis, and income in Euros, ttest analysis for dichotomous categorical, univariate analysis for multicategorical and correlation analysis (Spearman) for continuous data were performed $(n=192)$. 


\section{Course of HRQL}

The differences between HRQL at $\mathrm{t}=0$ and follow up were investigated with analysis of variance (ANOVA) and t-tests for Equality of Means ( $\mathrm{n}=120)$.

Explanatory variables on the course of HRQL

a) Effects of response to treatment on the course of $H R Q L$ The course of HRQL was analyzed separately for patients with SVR, relapse or non-response with t-tests. Comparison between patients with SVR, with relapse and non-response was assessed by means of ANOVA.

b) Effects of treatment schedule The mean differences in quality of life between $t=0$ and follow up were compared between patients treated with standard and individualized treatment using ANOVA and t-tests for Equality of Means. Also the mean differences were compared between the groups with RVR (A1, A2 and standard treatment with RVR) and the groups B2, D and A2 (extended versus shortened therapy, see Figure 1).

c) Effects of patient characteristics on the course of $H R Q L$ With t-test analysis for dichotomous categorical, univariate analysis for multicategorical and correlation analysis (Spearman) for continuous data, the influence on the differences between HRQL at $t=0$ and follow up was determined for the factors age $(<20,20-29,30-$ 39 , 40-49, 50-59, 60-69 years), gender, participating center, presence of cirrhosis, genotype $(1,4$, and 5 versus 2 and 3) and income in Euros.

d) Multivariate analysis For further exploration of the influence of the different factors mentioned above on the course of HRQL, a multivariate analysis was performed with a correction for age and baseline values of the SF-36.

\section{Results}

Baseline host and virus-related variables were similar in the standard and the individualized treatment groups (data not shown).

\section{Determinants of HRQL before treatment}

HRQL varied with age, participating center, severity of liver disease and income in Euros (Table 1). As might be expected, younger patients had a better performance compared to older patients, especially on the physical components of HRQL. Surprisingly, cirrhotic patients had a better performance than non-cirrhotic patients, having significantly higher scores on several dimensions of the SF-36, mostly on mental components. Higher income in Euros had a weak positive effect on the physical component summary scale and role limitation because of physical health scale of HRQL, with a correlation coefficient of $0.30(\mathrm{p}=.003)$ and $0.23(\mathrm{p}=.002)$ respectively. Finally, HRQL differed among the different participating centers: the mental component summary scale and the dimensions physical functioning, role limitation because of physical health, general health, bodily pain, vitality, social functioning and mental health were all significantly different between the participating centers (Figure 2).

\section{Course of HRQL}

General health improved significantly at follow up compared to general health at start of treatment (mean improvement $3.5, \mathrm{p}=.04$ ). The subscale physical functioning tended to worsen with a mean decrease of - 3.4 $(\mathrm{p}=.06)$ compared to $\mathrm{t}=0$. Other dimensions did not change.

\section{Explanatory variables on the differences between HRQL at baseline and at follow up a) Effect of response to treatment on course of $H R Q L$}

In patients with SVR, as well as with a relapse or nonresponse, HRQL did not change compared to $t=0$ after treatment with PEGIFN antiviral therapy, except for an increase in social functioning in sustained viral responders (78.8 at baseline, 83.3 at follow up, p = .04). Among the different groups changes compared to baseline in the dimensions general health differed significantly $(\mathrm{p}=.02)$ between patients with a relapse $(+5.3)$, SVR (+ 6.1) and non-response (- 6.3) to treatment.

\section{b) Effect of treatment schedule on course of HRQL}

No significant differences were observed in changes in the different dimensions of the SF-36 between standard and individualized treatment. A sub-analysis comparing responders and non-responders separately in standard and individualized treatment showed no difference, either. Patients treated for 24 weeks and patients treated with double dose PEGIFN showed a decline on the dimensions mental health whereas patients treated for 72 weeks had an increase on this dimension: respectively - 7.9, -2.0 and +18.5 .

\section{c) Effects of patient characteristics on course of HRQL}

Neither age, genotype nor grade of fibrosis had an influence on changes in the different dimensions of HRQL. A significant difference was seen between men and women in the dimensions bodily pain (males: +4.1 , females: $-7.2, \mathrm{p}=.02$ ), social functioning (males: +6.3 , females: $-5.8, \mathrm{p}=.008$ ), vitality (males: +7.2 , females: $2.7, \mathrm{p}=.03)$ and role limitations due to emotional problems (males: +9.3 , females: $-8.3, \mathrm{p}=.05$ ). There was a weak significant positive correlation between income in Euros and increase in vitality and mental health between baseline and follow up: correlation coefficient .30 ( $\mathrm{p}=$ $.02)$ for vitality and $.21(\mathrm{p}=.03)$ for mental health. See Figure 3 and 4 .

\section{d) Multivariate analysis}

Also in a multivariate analysis gender was a significant factor on the course of HRQL. All different dimensions, except for physical component summary scale and 
Table 1 Determinants of Health Related Quality of Life on $\mathbf{t}=\mathbf{0}$ and course of Health Related Quality of Life

\begin{tabular}{|c|c|c|c|c|c|}
\hline & Subscale & $t=0$ & P-value & $\begin{array}{l}\text { Course } \\
(\text { follow up }-t=0)\end{array}$ & P-value \\
\hline \multirow[t]{3}{*}{ Age } & & $\begin{array}{l}\text { Age category (20-29, 30-39, } \\
40-9,50-59)\end{array}$ & & $\begin{array}{l}\text { Age category }(20-29,30-39, \\
40-49,50-59)\end{array}$ & \\
\hline & Physical functioning & $90.6,93.1,86.1,78.1$ & 0.01 & & \\
\hline & Subscale & $t=0$ & P-value & $\begin{array}{l}\text { Course } \\
(\text { follow up }-t=0)\end{array}$ & P-value \\
\hline \multirow[t]{7}{*}{ Cirrhosis No/Yes } & & Yes & & Yes & \\
\hline & Mental component summary scale & 53.7 & 0.001 & & \\
\hline & General health & 61.3 & 0.003 & & \\
\hline & Bodily pain & 74.2 & 0.04 & & \\
\hline & Role limitation because of emotional problems & 68.9 & 0.05 & & \\
\hline & Mental health & 80.4 & 0.0004 & & \\
\hline & Subscale & $t=0$ & P-value & $\begin{array}{l}\text { Course } \\
\text { (follow up }-t=0 \text { ) }\end{array}$ & P-value \\
\hline \multirow[t]{7}{*}{ Income in Euros } & Subscale SF-36 & Correlation coefficient & P-value & Correlation coefficient & P-value \\
\hline & Physical component summary scale & 0.30 & 0.003 & & \\
\hline & Role limitation because of physical health & 0.23 & 0.002 & & \\
\hline & Vitality & & & .30 & 0.02 \\
\hline & Bodily pain & 0.18 & 0.07 & & \\
\hline & Mental health & & & .21 & 0.03 \\
\hline & Subscale & $t=0$ & P-value & $\begin{array}{l}\text { Course } \\
(\text { Follow up }-t=0)\end{array}$ & P-value \\
\hline \multirow[t]{5}{*}{ Gender (M/F) } & & $M$ & & $M$ & \\
\hline & Bodily pain & & & +4.1 & 0.02 \\
\hline & Social functioning & & & +6.3 & 0.008 \\
\hline & Vitality & & & +7.2 & 0.03 \\
\hline & Role limitation because of emotional problems & & & +9.3 & 0.05 \\
\hline
\end{tabular}

Results of statistical analysis of the influence of age (ANOVA), presence of cirrhosis (t-test), gender (t-test) and income in Euros (correlation analysis: Spearman) on Health Related Quality of Life at start of treatment $(t=0)$ and the course of Health Related Quality of Life (scores at 24 weeks after treatment (Follow up) minus scores at baseline). Data were shown if relationships were statistically significant.
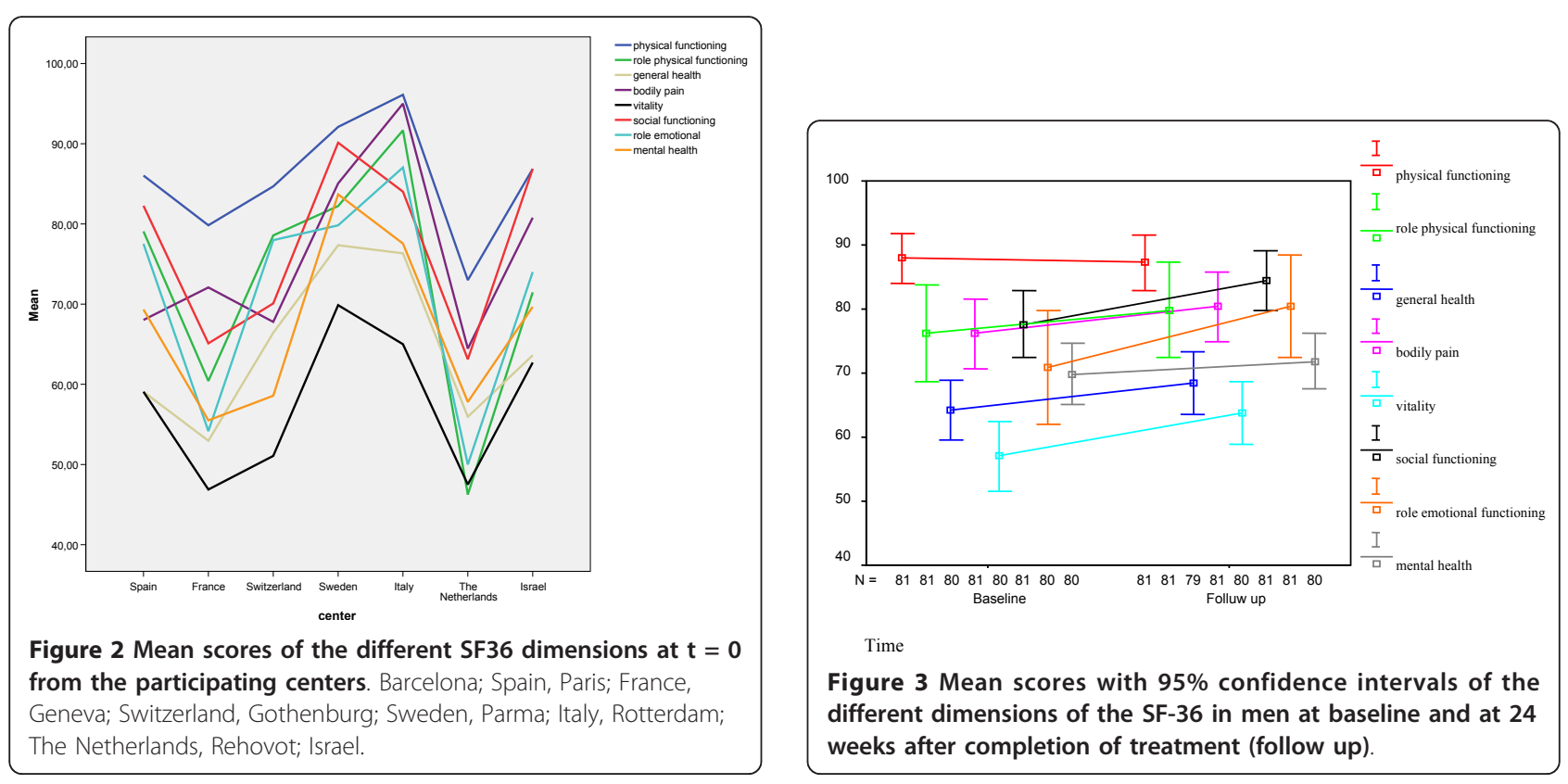


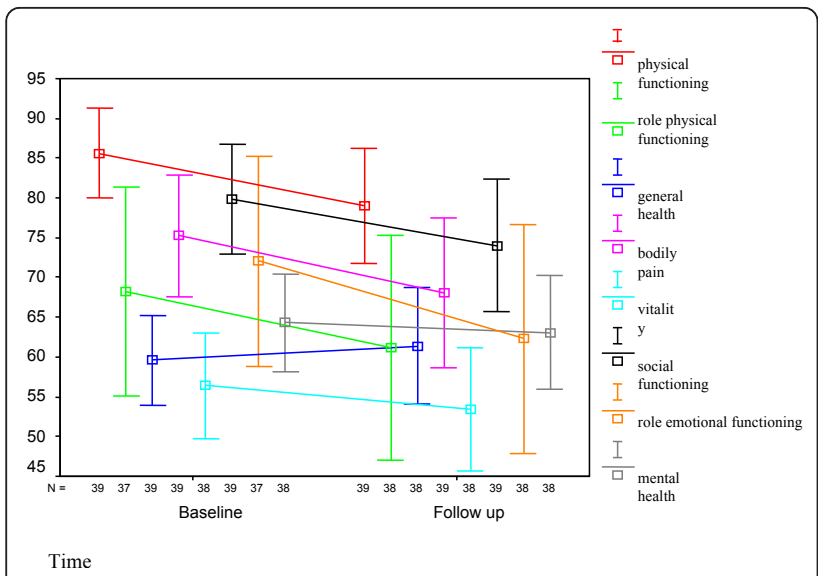

Figure 4 Mean scores with $95 \%$ confidence intervals of the different dimensions of the SF-36 in females at baseline and at 24 weeks after completion of treatment (follow up).

general health, were significantly different between men and women (Table 2). Response to treatment was again significantly influencing general health.

In the multivariate analysis, individualized treatment had a significantly negative influence on the course of HRQL on the dimensions physical component summary scale, bodily pain, vitality and social functioning, compared to patients treated with standard treatment (Table 2).

The presence or absence of cirrhosis and grade of fibrosis did not play a role in the course of HRQL in this analysis. Also different kind of genotypes (1, 4 and 5 versus 2 and 3 ) did not influence changes in HRQL.

\section{Discussion}

In this study we explored the influence of PEGIFNbased antiviral treatment with various regimens and of patients characteristics on HRQL before as well as at 24 weeks after completion of treatment. Main determinants of HRQL in this study were the severity of liver disease (non-cirrhosis vs. cirrhosis), age, gender and participating center and - to some extent - response to treatment.
With regard to the severity of the liver disease, patients with cirrhosis did better compared to those without cirrhosis. We are unable to explain this difference.

In our study almost all dimensions of the SF-36 did not change regardless of response, indicative of a satisfying recovery of patients after cytokine-based therapy. However, a significant increase was found on the subscale general health despite a therapy-induced worsening of the subscale physical functioning. This improvement was seen in patients with both SVR and relapse, whereas non-responders showed a decrease in general health. In our study, interestingly the relapsers who were ignorant of treatment effect when filling in the questionnaire, had a far more higher score on general health compared to the non-responders who were aware of their previous non-response to therapy. This underlines the mental aspects of the impact on HRQL in this disease [14]. The observed recovery in HRQL is in line with previous studies reporting an improvement on (almost) all different dimensions of the SF-36 after a successful treatment with PEGIFN and RBV compared to baseline scores [2,8-10].

The presence of cirrhosis did not influence the course of HRQL during treatment, but patients with a cirrhosis had higher scores on some, mostly mental, dimensions of the SF-36 at $\mathrm{t}=0$ and at follow up, which is in contrast with earlier studies $[8,15]$. Patients with decompensated cirrhosis were excluded to participate in the study, but still we cannot explain this difference. Higher age was associated with a decrease in HRQL, according to literature data [16].

Men and women differed in the course of HRQL with an increase on scores for men on several dimensions and women experiencing a decrease. These differences between men and women were also significant in a multivariate analysis for all dimensions except for general health. In the general population, men report a higher HRQL [16-18], a finding possibly of relevance for our findings. But also, therapy with PEGIFN and RBV might have a more intense and more prolonged impact on

Table 2 Multivariate analysis

\begin{tabular}{|c|c|c|c|c|c|c|c|c|c|c|}
\hline & $\begin{array}{l}\text { Physical } \\
\text { component } \\
\text { summary } \\
\text { scale }\end{array}$ & $\begin{array}{l}\text { Mental } \\
\text { component } \\
\text { summary } \\
\text { scale }\end{array}$ & $\begin{array}{c}\text { Physical } \\
\text { functioning }\end{array}$ & $\begin{array}{c}\text { Role limitation } \\
\text { because of } \\
\text { physical } \\
\text { health }\end{array}$ & $\begin{array}{l}\text { General } \\
\text { health }\end{array}$ & $\begin{array}{l}\text { Bodily } \\
\text { pain }\end{array}$ & Vitality & $\begin{array}{c}\text { Social } \\
\text { functioning }\end{array}$ & $\begin{array}{l}\text { Role limitation } \\
\text { because of } \\
\text { emotional } \\
\text { problems }\end{array}$ & $\begin{array}{l}\text { Menta } \\
\text { health }\end{array}$ \\
\hline Gender & & .043 & .050 & .030 & & .006 & .009 & .001 & .024 & .023 \\
\hline SVR & & & & & .047 & & & & & \\
\hline $\begin{array}{l}\text { Standard vs } \\
\text { Individualized } \\
\text { treatment }\end{array}$ & .031 & & & & & .019 & .027 & .031 & & .075 \\
\hline
\end{tabular}

Multivariate analysis (corrected for baseline value and age) of the influence of gender, response to treatment and kind of therapy on the mean difference between baseline and follow up (course of Health Related Quality of Life) of the different dimensions of the SF- 36.

Only significant $p$-values are shown in this table.

Abbreviations: Sustained Virological Response (SVR). 
females. Studies show more severe anemia in women during treatment with PEGIFN and RBV [19]. As anemia plays an important role in HRQL during antiviral treatment this could be one of the explanations for the observed difference [20]. With the fixed doses of PEGIFN women may be treated with higher doses of PEGIFN per $\mathrm{kg}$, which may contribute to more sideeffects and a lower HRQL during treatment and at 24weeks follow-up. To our knowledge, only one study found sex differences in recovery, with males doing slightly worse [21].

HRQL at baseline was found to be differing between the participating centers (in this case different countries/cultural regions). In the study by Ware et al [9] a similar observation was made. Although much attention has been devoted to assure the comparability between different cultures and languages, this observation suggests that studies from different countries concerning side effects (for instance decrease of HRQL, but also psychopathology) should be interpreted with caution $[22,23]$.

An important limitation of this study is the large number of variables in relation to the number of participants and the many different treatment schedules. Also the relative high number of drop-outs with data of 192 patients at baseline and of 128 patients at follow up could be of importance, however non-responders or relapsers were not significantly more non-compliant compared to responders (data not shown). In retrospect an additional time point at the end of treatment would have given more insight.

\section{Conclusion}

In conclusion: our findings support the observation, that in general patients exposed to PEGIFN-based treatment do recover to their pre-treatment level of baseline, six months after completion of antiviral therapy or even surpass that level. This underlines again the safe profile of this intensive treatment, irrespective of the used dosage and/or duration in this study. Before treatment and after treatment with PEGIFN in patients chronically infected with HCV health related quality of life is mostly influenced by presence of cirrhosis, age, gender, participating center (or country) and response to treatment. Also, awareness of response status to therapy seems important.

\footnotetext{
Author details

${ }^{1}$ Dpt. Gastroenterology \& Hepatology, Erasmus University Medical Center, Rotterdam, the Netherlands. ${ }^{2}$ Yulius Academy, Yulius, Organization for Mental Health, Rotterdam, the Netherlands. ${ }^{3}$ Dpt. Gastroenterology, Sourasky Medical Center, Tel-Aviv, Israel. ${ }^{4}$ Dpt. Internal Medicine-Hepatology, Hospital General Vall d'Hebron, Barcelona, Spain. ${ }^{5}$ Dpt. Infectious Diseases, University of Gothenburg, Gothenborg, Sweden. ${ }^{6}$ Dpt. Gastroenterology \& Hepatology,

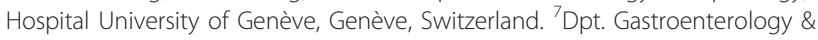

Hepatology, Johann Wolfgang Goethe Hospital, Frankfurt, Germany. ${ }^{8}$ Dpt. Infectious Diseases and Hepatology, Azienda Ospedaliera di Parma, Parma, Italy. ${ }^{9}$ Dpt. Virology, Hopital Henri Mondor - Université Paris XII, Creteil, France. ${ }^{10}$ Mina and Everard Goodman Faculty of Life Sciences, Bar-llan University, Ramat-Gan, Israel.

\section{Authors' contributions}

GB contributed to the design of the study, acquired and analysed the data, and drafted the manuscript; AG contributed to the design of the study, analysis of the data and was involved in drafting the masnuscript; EVH contributed to the analysis of the data; $\mathrm{BH}$ contributed to the statistical analysis of the data; $Y L$ contributed to data-acquirement and revision of the manuscript; JE contributed to data-acquirement and revision of the manuscript; ML contributed to data-acquirement and revision of the manuscript; FN contributed to data-acquirement and revision of the manuscript; SZ contributed to design of the study, data-acquirement and revision of the manuscript, CF contributed to data-acquirement and revision of the manuscript; JMP contributed to data-acquirement and revision of the manuscript; AUN contributed to data acquirement and revision of the manuscript; SWS contributed to the design of the study, data-acquirement and revision of the manuscript; RJK contributed to the design of the study, data-requirement and analysis, and drafting the manuscript. All authors have read and approved the final manuscript.

\section{Competing interests}

This study was supported by the European Community (QLK2-2000-00836), Hoffmann La-Roche and Maxim Pharmaceuticals.

In addition and in relation to this study, the authors would like to disclose the following:

Geert Bezemer, nothing to disclose

Arthur R. Van Gool, nothing to disclose

Elke Verheij-Hart, nothing to disclose

Bettina E. Hansen, nothing to disclose

Yoav Lurie, nothing to disclose

Juan I. Esteban, nothing to disclose

Martin Lagging, nothing to disclose

Francesco Negro, nothing to disclose

Stefan Zeuzem, nothing to disclose

Carlo Ferrari, nothing to disclose

Jean-Michel Pwalotsky, nothing to disclose

Avidan Neumann, nothing to disclose

Solko W. Schalm, nothing to disclose

Robert J. de Knegt, nothing to disclose

Received: 28 July 2011 Accepted: 31 January 2012

Published: 31 January 2012

\section{References}

1. Foster GR, Goldin RD, Thomas HC: Chronic hepatitis C virus infection causes a significant reduction in quality of life in the absence of cirrhosis. Hepatology 1998, 27:209-212.

2. Spiegel BM, Younossi ZM, Hays RD, Revicki D, Robbins S, Kanwal F: Impact of hepatitis $C$ on health related quality of life: a systematic review and quantitative assessment. Hepatology 2005, 41:790-800.

3. Castera L, Constant A, Bernard PH, de Ledinghen V, Couzigou P. Psychological impact of chronic hepatitis C: comparison with other stressful life events and chronic diseases. World I Gastroenterol 2006, 12:1545-1550.

4. Rodger AJ, Jolley D, Thompson SC, Lanigan A, Crofts N: The impact of diagnosis of hepatitis C virus on quality of life. Hepatology 1999, 30:1299-1301.

5. Niederau C, Bemba G, Kautz A: [Socioeconomic characteristics, quality of life, and state of knowledge of patients with hepatitis $C$ viral infection in Germany-socioeconomic aspects in hepatitis C]. Z Gastroenterol 2006, 44:305-317.

6. Dantzer R, O'Connor JC, Freund GG, Johnson RW, Kelley KW: From inflammation to sickness and depression: when the immune system subjugates the brain. Nat Rev Neurosci 2008, 9:46-56.

7. Weissenborn K, Krause J, Bokemeyer M, Hecker H, Schuler A, Ennen JC, Ahl B, Manns MP, Boker KW: Hepatitis C virus infection affects the brain- 
evidence from psychometric studies and magnetic resonance spectroscopy. J Hepatol 2004, 41:845-851.

8. Bonkovsky HL, Woolley JM: Reduction of health-related quality of life in chronic hepatitis $C$ and improvement with interferon therapy. The Consensus Interferon Study Group. Hepatology 1999, 29:264-270.

9. Ware JE Jr, Bayliss MS, Mannocchia M, Davis GL: Health-related quality of life in chronic hepatitis C: impact of disease and treatment response. In Hepatology. Volume 30. The Interventional Therapy Group; 1999:550-555.

10. McHutchison JG, Ware JE Jr, Bayliss MS, Pianko S, Albrecht JK, Cort S, Yang I, Neary MP, Hepatitis Interventional Therapy Group: The effects of interferon alpha- $2 b$ in combination with ribavirin on health related quality of life and work productivity. J Hepatol 2001, 34:140-147.

11. Hassanein T, Cooksley G, Sulkowski M, Smith C, Marinos G, Lai MY, Pastore G, trejo-Estrada R, Horta E, Vale A, Wintfield N, green J: The impact of peginterferon alfa-2a plus ribavirin combination therapy on healthrelated quality of life in chronic hepatitis C. J Hepatol 2004, 40:675-681.

12. Zeuzem S, Pawlotsky JM, Lukasiewicz E, von Wagner M, Goulis I, Lurie Y, Gianfranco E, Vrolijk JM, Esteban Jl, Hezode C, Lagging M, Negro F, Soulier A, Verheij-Hart E, Hansen B, Tal R, Ferrari C, Schalm SW, Neumann AU, DITTO-HCV Study Group: International, multicenter, randomized, controlled study comparing dynamically individualized versus standard treatment in patients with chronic hepatitis C. J Hepatol 2005, 43:250-257.

13. Ware JE Jr, Kosinski M, Bayliss MS, McHorney CA, Rogers WH, Raczek A: Comparison of methods for the scoring and statistical analysis of SF-36 health profile and summary measures: summary of results from the Medical Outcomes Study. Med Care 1995, 33(Suppl):AS264-79.

14. Wessely S, Pariante C: Fatigue, depression and chronic hepatitis C infection. Psychol Med 2002, 32:1-10.

15. Kallman J, O'Neil MM, Larive B, Boparai N, Calabrese L, Younossi ZM: Fatigue and health-related quality of life (HRQL) in chronic hepatitis C virus infection. Dig Dis Sci 2007, 52:2531-2539.

16. Ware JE Jr, Kosinski M, Gandek B: SF-36 Health Survey Manual and Interpretation Guide. Boston, MA: New England Medical Center, The Health Institute; 1993.

17. Aaronson NK, Muller M, Cohen PD, Essink-Bot ML, Fekkes M, Sanderman R, Sprangers MA, te Velde A, Verrips E: Translation, validation, and norming of the Dutch language version of the SF-36 Health Survey in community and chronic disease populations. J Clin Epidemiol 1998, 51:1055-1068

18. Lewin-Epstein N, Sagiv-Schifter T, Shabtai EL, Shmueli A: Validation of the 36-item short-form Health Survey (Hebrew version) in the adult population of Israel. Med Care 1998, 36:1361-1370.

19. Sulkowski MS, Wasserman R, Brooks L, Ball L, Gish R: Changes in haemoglobin during interferon alpha-2b plus ribavirin combination therapy for chronic hepatitis C virus infection. J Viral Hepat 2004, 11:243-250.

20. Pockros PJ, Shiffman ML, Schiff ER, Sulkowski MS, Younossi Z, Dieterich DT, Wright TL, Mody SH, Tang KL, Goon BL, Bowers PJ, Leitz G, Afdhal NH, PROACTIVE Study Group: Epoetin alfa improves quality of life in anemic HCV-infected patients receiving combination therapy. Hepatology 2004, 40:1450-1458.

21. Bonkovsky HL, Snow KK, Malet PF, Back-Madruga C, Fontana RJ, Sterling RK, Kulig CC, Di Bisceglie AM, Morgan TR, Dienstag JL, Ghany MG, Gretch DR, HALT-C Trial Group: Health-related quality of life in patients with chronic hepatitis C and advanced fibrosis. J Hepatol 2007, 46:420-431.

22. Wagner AK, Gandek B, Aaronson NK, Acquadro C, Alonso J, Apolone G, Bullinger M, Bjorner J, Fukuhara S, Kaasa S, Leplege A, Sullivan M, WaudDauphinee S, Ware JE Jr: Cross-cultural comparisons of the content of SF36 translations across 10 countries: results from the IQOLA Project. International Quality of Life Assessment. J Clin Epidemiol 1998, 51:925-932.

23. Bullinger M, Alonso J, Apolone G, Leplege A, Sullivan M, WoodDauphinee S, Gandek B, Wagner A, Aaronson N, Bech P, Fukuhara S, Kasa S, Ware JE Jr: Translating health status questionnaires and evaluating their quality: the IQOLA Project approach. International Quality of Life Assessment. J Clin Epidemiol 1998, 51:913-923.

\section{Pre-publication history}

The pre-publication history for this paper can be accessed here:

http://www.biomedcentral.com/1471-230X/12/11/prepub
doi:10.1186/1471-230X-12-11

Cite this article as: Bezemer et al:: Long-term effects of treatment and response in patients with chronic hepatitis $C$ on quality of life. An international, multicenter, randomized, controlled study. $B M C$

Gastroenterology 2012 12:11.

\section{Submit your next manuscript to BioMed Central and take full advantage of:}

- Convenient online submission

- Thorough peer review

- No space constraints or color figure charges

- Immediate publication on acceptance

- Inclusion in PubMed, CAS, Scopus and Google Scholar

- Research which is freely available for redistribution

Submit your manuscript at www.biomedcentral.com/submit
Ciomed Central 